SECTION 7. Mechanics and machine construction.

Alexandr Nikolayevich Shevtsov candidate of technical sciences, corresponding member of KazNANS,

President of IA T\&AS (USA, Sweden, Kazakhstan), Department of «Mathematics», Deputy Director on Science of faculty of information technologies, automation and telecommunications, Taraz state University named after M.Kh. Dulati, Kazakhstan Shev_AlexXXXX@mail.ru

Seysen Zaurbekovich Kazakbaev candidate of technical Sciences, corresponding member RAM, Taraz innovation and humanities university, Kazakhstan seisen58@mail.ru

Nurlan Syrymbayevich Karymsakov candidate of technical Sciences, senior lecturer, Taraz state University named after M.Kh.Dulati,Kazakhstan karymsakov.nurlan@mail.ru

Polatbek Kaldibaevich Seytpanov candidate of technical Sciences, Associate Professor, Taraz state University named after M.Kh. Dulati, Kazakhstan

Murat Musabekovich Bekmuratov Candidate of technical Sciences, Associate Professor, professor TARSU, Taraz state University named after M.Kh. Dulati, Kazakhstan

\title{
ABOUT SOME FEATURES OF BURNING FLAME
}

Abstract: The article examines the features of the theory, mathematical models and experimental data of process of burning gas.

Key words: fire, gas, current, model, a torch.

\section{О НЕКОТОРЫХ ОСОБЕННОСТЯХ ГОРЕНИЯ ПЛАМЕНИ}

Аннотация: В статье рассматриваются особенности теории, математические модели и опытные данные процесса горения газа.

Ключевые слова: пламя, газ, течение, модель, факел.

При различных технологических производствах в устройствах используются газовые пламена, металлургические печи, системы термического обезвреживания и других. Поэтому рассмотрение процесса горения газа в промышленных горелках, является достаточно важной задачей. Для повышения тепловой эффективности устройств и снижения экологически опасных выбросов необходимо знать наиболее рациональный режим сжигания топлива, расположения и оптимальные размеры сопел горелки. Постановка эксперимента очень трудоемкий и не всегда реализуемый процесс. Поэтому, целесообразно использовать математическое моделирование процессов происходящих при горении газового топлива. Процесс горения газового топлива, как правило, реализуется путем организации струйных течений.[1] 
Важность процесса горения в технических устройствах вместе с дороговизной натурных экспериментов способствует быстрому развитию компьютерного моделирования горения [2]. Модели процессов горения основаны на законах сохранения массы, импульса и энергии в многокомпонентной реагирующей смеси. Уравнения теории горения - это уравнения непрерывности для смеси в целом и всех отдельных компонентов, уравнение Навье-Стокса для сжимаемой среды и уравнение переноса тепла с химическими источниками. С подробными кинетическими схемами эта система дифференциальных уравнений в частных производных чрезвычайно сложна, и до настоящего времени не существует универсальных численных схем, которые могли бы применяться во всех режимах горения и температурных диапазонах. Поэтому такие схемы строятся для частных случаев, позволяющих дополнительно упростить систему уравнений. В качестве тестовой задачи рассмотрим [1] метановую горелку Sandia, разработанную университетом Сиднея.

В одномерном случае для медленного горения (ламинарное пламя) разработаны эффективные методы решения системы уравнений, в том числе для подробных кинетических схем, и доступны пакеты программ, решающих эти задачи. В исследованиях чаще всего используются коммерческие пакеты CHEMKIN и Cosilab, a также свободное ПО Cantera [3].

В двух- и трёхмерном случаях до сих пор чаще всего применяется глобальная кинетическая схема. Такой подход реализован, например, в пакетах ANSYS FLUENT и KIVA, однако вместе с увеличением мощности компьютеров появляются и расчёты с сокращёнными кинетическими схемами и подробными схемами [4,5].

Двумерная осесимметричная геометрия состоит из основной горелки диаметром 7.2 мм, в которой горит смесь $25 \%$ метана и $75 \%$ сухого воздуха, и направляющего входа диаметром 18.2 мм, сжигающего смесь пилот-газа. Состав пилот-газа: 73,2\% азота, 5,1\% кислорода, 14,6\% углекислого газа и 7,1\% паров воды [1].

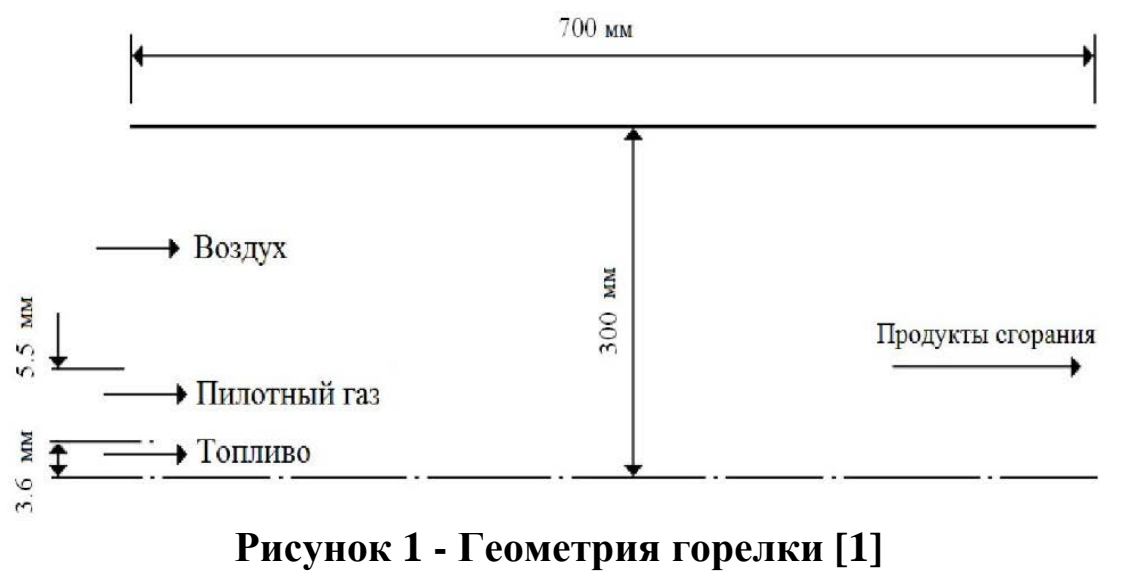

Для расчета горения часто используют две модели :

- гибридная модель (обрыв турбулентного вихря), по которой в качестве результирующей скорости выбирается наименьшая из скоростей.

$$
R_{i}=-M I N\left(\left|R_{i, K I N}\right|,\left|R_{i, E B U}\right|\right)
$$

- $\quad$ flamelet модель. Скорость перемешивания характеризуется скоростью скалярной диссипации $\chi=2 D(\nabla \xi)^{2}$,которая связана со скоростью деформации а. 
Горение метана сложный термохимический процесс. Существует множество механизмов описания горения метана в воздухе, начиная от самого простого в одну реакцию и заканчивая детальными, содержащими несколько десятков реакций.

\section{Ламинарное горение пламени и основные уравнения теории распространения пламени.}

Процесс распространения пламени характеризуется нормальной скоростью распространения $u_{n}$ - линейная скорость перемещения зоны горения по отношению к исходной смеси. Она измеряется по нормали к фронту. Эта скорость может быть оценена как объём газовой смеси сгорающей за единицу времени на единице площади фронта, т.е. $u_{n}=\frac{V}{S}$.

Вторая характеристика пламени - его толщина $\delta$. Иногда процесс горения характеризуется массовой скоростью горения $u_{m}=\rho u_{n}$, произведением плотности на нормальную скорость горения. Механизм распространения горения основывается на передаче тепла и активных центров между зоной горения и свежей смесью благодаря значительным градиентам температуры и концентрации вещества.

Пусть фронт пламени неподвижен, горючая смесь движется со скоростью и, температура меняется от начальной $T_{0}$ до конечной температуры горения $T_{g}$. Концентрация исходных веществ меняется от начальной $C_{0}$ до 0 . Изменение всех параметров горючей смеси показано на рис. 2.

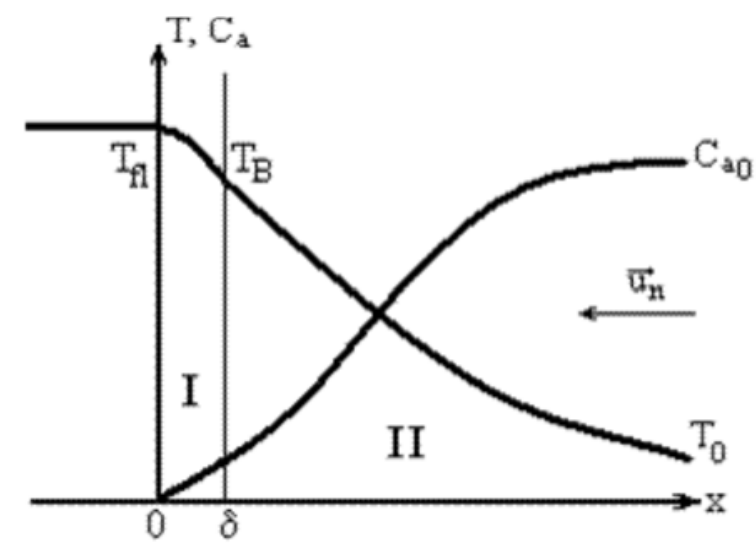

Рисунок 2 - Изменеие температуры и концентрации горючего в ламинарном пламени [6]

Будем предполагать, что теплоёмкость и коэффициент теплопроводности не зависят от температуры, и учитываем только одномерный перенос тепла Потери тепла в боковые стенки и за счёт излучения не учитываются. Уравнение сохранения энергии для элемента объёма запишется так

$$
c_{p} \frac{\partial T}{\partial t}=\lambda \frac{\partial^{2} T}{\partial x^{2}}-c_{p} \rho u \frac{\partial T}{\partial x}+H W
$$

Левая часть этого уравнения выражает количество теплоты в единице объёма за единицу времени. В правой части первое слагаемое описывает изменение количества тепла за счёт теплопроводности, второе - за счёт нагрева поступающей смеси, третье - 
за счёт химической реакции. Всвязи с тем, что поступающая смесь неизменна по составу и параметрам то ищем стационарное решение $u=$ const , тогда

$$
\lambda \frac{d^{2} T}{d x^{2}}-c_{p} \rho u \frac{d T}{d x}+H W=0
$$

В зоне пламени будет наблюдаться перенос не только тепла, но и вещества, вследствие наличия градиента концентраций, Концентрация вещества в зоне реакции, т.о., будет определяться не только химической реакцией, но и диффузией. Уравнение диффузии имеет вид [6]

$$
\frac{d}{d t} D \rho \frac{d c}{d x}-u \rho \frac{d c}{d x}-W=0
$$

где D - коэффициент диффузии. Первое слагаемое описывает изменение концентрации вещества за счёт диффузии, второе - за счёт конвекции, общего движения газа, третье за счёт химической реакции.

Введём в уравнение (2) энтальпию

$$
d i=c_{p} d t
$$

Тогда получим уравнение

$$
\frac{d}{d x} \frac{\lambda}{c_{p}} \frac{d c}{d x}-\rho u \frac{d c}{d x}+H W=0
$$

Сделав допущение о равенстве коэффициентов диффузии и температуропроводности [6]

$$
D=a=\frac{\lambda}{c_{p} \rho}
$$

тоже самое, что число Льюиса равно единице $L e=\frac{D}{a}=1$. Умножив уравнение (3) на Н с сложив с (5) получим

$$
\frac{d}{d x} \frac{\lambda}{c_{p}} \frac{d}{d x}(i+c H)-\rho u \frac{d}{d x}(i+c H)=0
$$

Решением этого уравнения при начальных условиях

будет

$$
x= \pm \infty \quad \frac{d}{d x}(i+c H)=0
$$

$$
i+c H=\text { const }
$$

т.е. полная энтальпия - сумма тепловой и химической энергии в ходе горения не меняется. Физически это означает, что диффузия из холодной зоны в зону горения полностью компенсируется переносом тепла в обратную сторону. Указанное равенство (8) справедливо при условии $L e=\frac{D}{a}=1$, что справедливо для газовых систем, в ином случае оно нарушается.[6] 


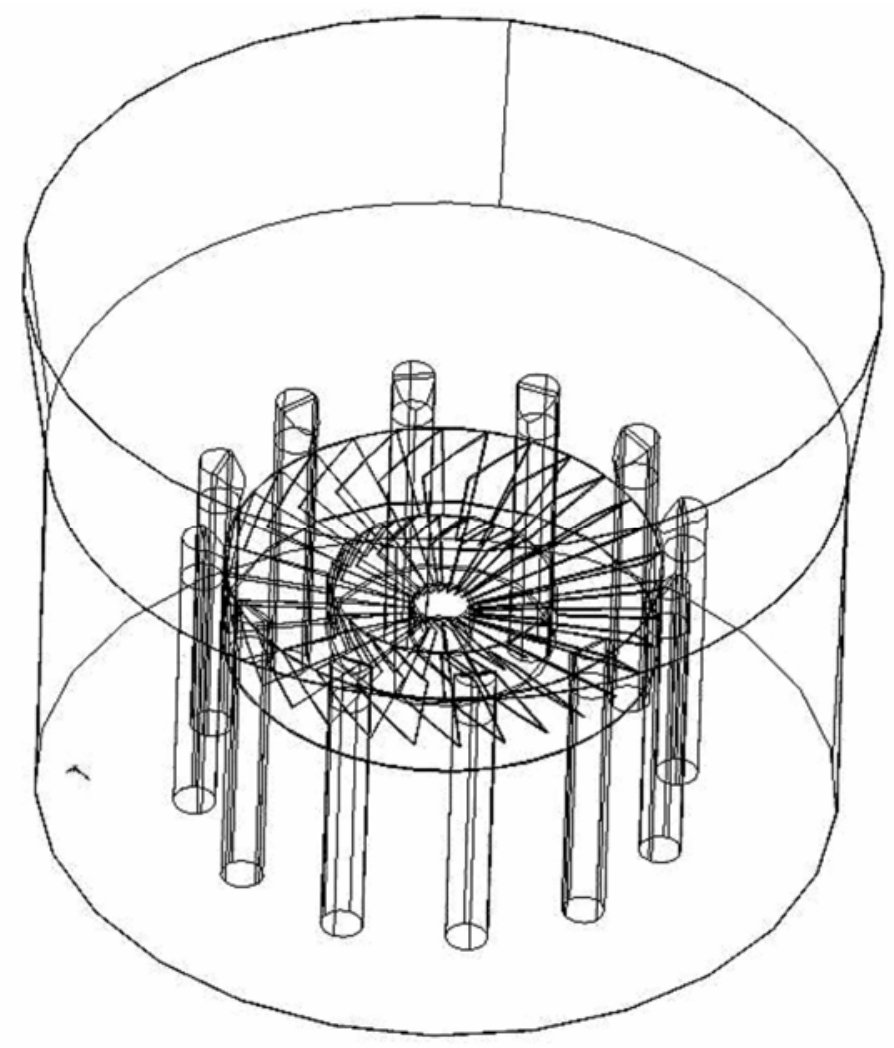

Рисунок 3 - Конструкция горелки.

Из (8) следует

$$
c_{p} T_{0}+c_{0} H=c_{p} T+c H=c_{p} T_{8}
$$

откуда

$$
c=c_{0} \frac{T_{g}-T}{T_{g}-T_{0}}
$$

или

$$
\frac{c_{0}-c}{c}=\frac{T-T_{0}}{T_{g}-T_{0}}
$$

Наличие такой связи позволяет выразить скорость химической реакции как функцию одной переменной - температуры или концентрации, а вместо решения двух дифференциальных уравнений ограничиться одним.

\section{Численное решение задачи о ламинарном распространении пламени[6].}

Скорость реакции существенна только при высоких температурах, тогда зону горения можно разделить на две области:

1. зона прогрева, в которой пренебрегаем химической реакцией

2. зона химической реакции, в которой пренебрегаем конвекцией. 
Для первой области уравнение теплопроводности запишется в виде

$$
\lambda \frac{d^{2} T}{d x^{2}}-c_{p} \rho u \frac{d T}{d x}=0
$$

Начало координат разместим на границе области [6].

\section{Для области 1}

$$
\lambda \frac{d^{2} T}{d x^{2}}-c_{p} \rho u \frac{d T}{d x}=0
$$

При начальных условиях

$$
\begin{aligned}
& x=-\infty \\
& T=T_{0} \\
& \frac{d T}{d x}=0 \\
& x=0 \\
& T=T^{\prime} \\
& \frac{d T}{d x}=\left(\frac{d T}{d x}\right)_{1}
\end{aligned}
$$

В этом случае тепловой поток из зоны 1 будет

$$
\left(\frac{d T}{d x}\right)_{1}=\frac{1}{\lambda} c_{p}\left(T^{\prime}-T_{0}\right)
$$

\section{Для области 2}

$$
\lambda \frac{d^{2} T}{d x^{2}}+H W=0
$$

Начальные условия

$$
\begin{aligned}
& x=0, \\
& T=T^{\prime}, \\
& \frac{d T}{d x}=\left(\frac{d T}{d x}\right)_{2} \\
& x=\infty, \\
& T=T_{g}, \\
& \frac{d T}{d x}=0 .
\end{aligned}
$$

Используем подстановку $p=\frac{d T}{d x}$ получим

$$
\lambda \frac{d p}{d x}+H W=0
$$

или

$$
\lambda \frac{d p}{d T} \frac{d T}{d x}+H W=0
$$

Окончательно получим

$$
\lambda p \frac{d p}{d T}+H W=0
$$

откуда

$$
\left(\frac{d T}{d x}\right)_{2}=\sqrt{\frac{2 H}{\lambda} \int_{T}^{T_{g}} W d T}
$$

Из условия равенства тепловых потоков получим [6]

$$
\frac{1}{\lambda} c_{p} \rho u\left(T^{\prime}-T_{0}\right)=\sqrt{\frac{2 H}{\lambda} \int_{T^{\prime}}^{T_{g}} W d T}
$$


Температуру на границе областей примем равной $T_{g}$, в интеграле заменим $T^{\prime}$ на $T_{0}$. Т.к. основной вклад будет вносить скорость при высоких температурах, величина интеграла изменится несильно. Тогда массовая скорость горения может быть записана как

$$
\rho u=\frac{\sqrt{\frac{2 H}{\lambda} \int_{T^{\prime}}^{T_{g}} W d T}}{c_{p}\left(T_{g}-T_{0}\right)}
$$

Для вычисления интеграла используем разложение Франк -Каменецкого [6]

$$
e^{-\frac{E}{R T}} \approx e^{-\frac{E}{R T_{g}}} e^{-\frac{E \Delta T}{R T_{g}^{2}}}
$$

где $\Delta T=T_{g}-T$. Из последнего равенства получим $d T=-d \Delta T$. При этом пределы интегрирования изменятся

$$
\begin{aligned}
& T=T_{g} \\
& \Delta T=0 \\
& T=T_{0} \\
& \Delta T=T_{g}-T_{0}
\end{aligned}
$$

Тогда получаем

$$
\int_{T_{0}}^{T_{g}} W d T=-\int_{T_{g}-T_{0}}^{0} k_{0} c^{v} e^{-\frac{E}{R T_{g}}} e^{-\frac{E \Delta T}{R T_{g}^{2}}} d \Delta T=k_{0} c^{v} e^{-\frac{E}{R T_{g}}} \frac{R T_{g}^{2}}{E} e^{-\frac{E \Delta T}{R T_{g}^{2}}}=k_{0} c^{v} e^{-\frac{E}{R T_{g}}} \frac{R T_{g}^{2}}{E}\left(1-e^{-\frac{E\left(T_{g}-T_{0}\right)}{R T_{g}^{2}}}\right)
$$

второе слагаемое в скобках для углеводородных топлив приближённо равно

$$
e^{-\frac{E\left(T_{g}-T_{0}\right)}{R T_{g}^{2}}} \approx e^{-\frac{40000 * 2000}{2 * 2000^{2}}} \approx e^{-10} \approx 0
$$

Первые три сомножителя перед скобками дают скорость реакции при температуре горения $W_{g}$. В итоге массовая скорость горения составит

$$
\rho u=\frac{\sqrt{2 \lambda H W_{g} \frac{R T_{g}^{2}}{E}}}{c_{p}\left(T_{g}-T_{0}\right)}
$$

Применяя уравнение неразрывности $\rho u=\rho_{0} u_{n}$ получим выражение для нормальной скорости горения

$$
u_{n}=\sqrt{\frac{2 \lambda H W_{g} R T_{g}^{2}}{\rho_{0}{ }^{2} C_{p}{ }^{2}\left(T_{g}-T_{0}\right)^{2} E}}
$$

В соответствии с равенством $\rho_{0} c_{p}\left(T_{g}-T_{0}\right)=H W_{g} t_{k}$, где в левой части стоит количество тепла выделяющееся в единице объёма, а в правой та же величина, 
выраженная через максимальную скорость реакции и её продолжительность $t_{k}$ и учитывая $\frac{\lambda}{\rho c_{p}}=a$ получим

$$
u_{n}=\sqrt{\frac{2 a}{t_{k}} \frac{R T_{g}^{2}}{E\left(T_{g}-T_{0}\right)}}=\sqrt{\frac{a}{t_{k}}} \sqrt{\frac{2 R T_{g}^{2}}{E\left(T_{g}-T_{0}\right)}}
$$

или

$$
u_{n}=B \sqrt{\frac{\lambda}{t_{k}}}
$$

Ширина зоны горения может быть найдена из уравнения (12) при условиях[6]

$$
\begin{aligned}
& x=-\infty \\
& \frac{d T}{d x}=0
\end{aligned}
$$

Первый интеграл будет

$$
\frac{d T}{d x}=\frac{1}{\lambda} c_{p} \rho u\left(T-T_{0}\right)
$$

Разделим переменные

$$
\frac{d T}{T-T_{0}}=\frac{c_{p} \rho u}{\lambda} d x
$$

и с учётом начальных условий $x=0, T=T_{g}$ получим

$$
\ln \left(T_{g}-T_{0}\right)-\ln \left(T-T_{0}\right)=\frac{c_{p} \rho u}{\lambda} x
$$

или

$$
\frac{T_{g}-T_{0}}{T-T_{0}}=e^{\frac{c_{p} \rho u}{\lambda} x}
$$

Порядок толщины зоны пламени $\delta$ можно оценить по характеристической толщине - расстоянии, на котором температура спадает в $e$ раз.[6]

$$
\frac{c_{p} \rho u_{n}}{\lambda} \delta=1
$$

откуда

$$
\delta=\frac{\lambda}{c_{p} \rho u_{n}}=\frac{a}{u_{n}}
$$

Сварочное пламя образуется в результате сгорания горючих газов или паров горючих жидкостей в смеси с техническим кислородом. При этом пламя имеет сложную структуру и строение, которое показано на рис.4-6. Качество газовой сварки во многом зависит от правильности регулировки пламени, которое сварщик выставляет «на глаз» по форме и цвету. Поэтому очень важно знать строение и структуру пламени газовой горелки, чтобы учитывать это в повседневной работе. Форму, цвет и структуру пламени горелки меняют соотношением ацетилена и кислорода, подаваемых в зону горения. В качестве примера рассмотрим ацетилено-кислородное пламя. 


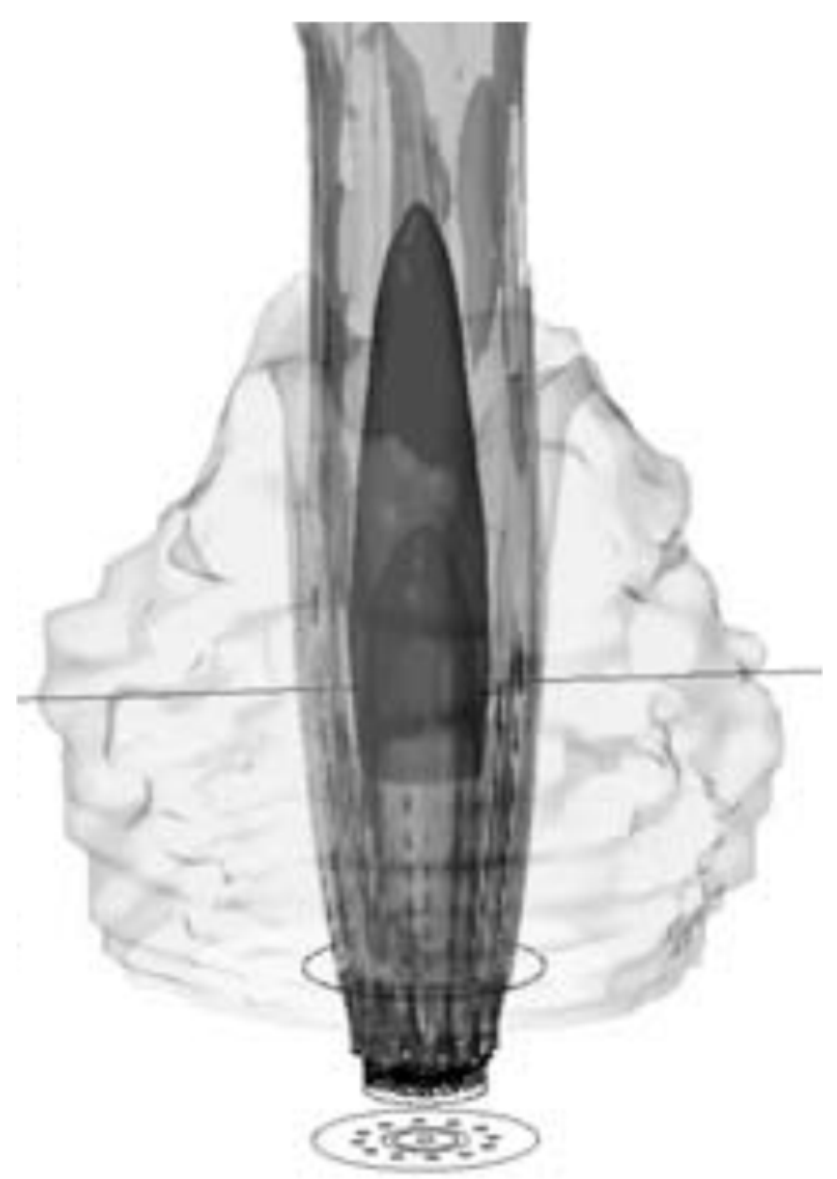

Рисунок 4 - Изоповерхности пламени.

Ядро пламени имеет форму цилиндра с заостренным концом, вокруг которого расположена ярко светящаяся оболочка. Длина ядра пламени регулируется скоростью подачи газовой смеси и ее качественным составом. Диаметр ядра зависит от размеров мундштука и расхода горючей смеси.

Строение пламени меняется при изменении соотношения смеси и может быть: нормальным, науглероженным и окислительным (рис.6).

Нормальное пламя получается, когда на один объем горючего газа подается один объем кислорода. Если в качестве горючего газа принят ацетилен, то процесс его нормального сгорания можно записать в следующем виде: С2Н2 -Ю2 = 2CO+ Н2.

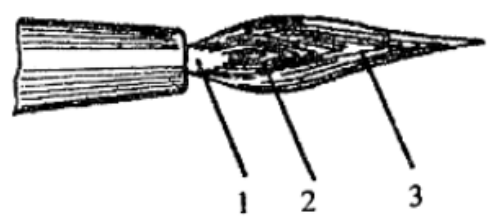

Рисунок 5 - Составляющие ацетилено-кислородного пламени: 1 - ядро; 2 восстановительная зона; 3 - факел пламени 


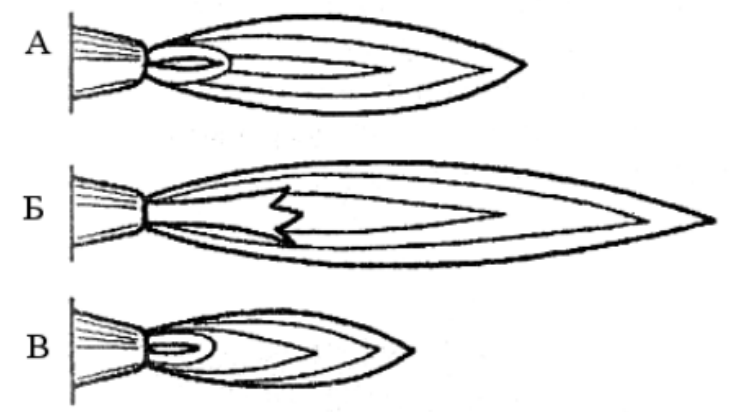

\section{Рисунок 6 - Разновидности ацетилено-кислородного пламени: А - нормальное; Б - науглераживающее; В — окислительное}

При этом продукты неполного сгорания догорают за счет кислорода, присутствующего в атмосферном воздухе. Так как абсолютно чистых веществ в природе не бывает и кислород содержит в себе некоторое количество примесей, то нормальное пламя получается при некотором его повышенном значении, то есть при соотношении ацетилена и кислорода, равном 1,1 -1,2. Ядро нормального пламени светлое со слегка затемненной восстановительной зоной и факелом. По форме ядро пламени напоминает цилиндр с четкими очертаниями и закругленным концом. Диаметр цилиндра зависит от размера мундштука сварочной горелки, а длина определяется скоростью истечения газовой смеси. Вокруг ядра пламени размещается светлая оболочка, в которой происходит сгорание раскаленных частиц углерода. При высокой скорости подачи газа пламя способствует сгоранию металла и выдуванию его из сварочной ванны. Малая скорость подачи газов чревата обратными ударами и хлопками.

Восстановительная зона пламени имеет более темный цвет и располагается в пространстве в пределах 20 мм от конца ядра. Температура пламени в этой зоне может достигать $3150^{\circ} \mathrm{C}$ (при сгорании ацетилена). Размер восстановительной зоны зависит от номера сварочного мундштука. При помощи этой зоны пламени нагревают метал, плавят его и ведут сварку. Остальная часть пламени, расположенная за восстановительной зоной, состоящая из углекислого газа, паров воды и азота, имеет значительно меньшую температуру.

Науглероженное пламя получается, когда соотношение ацетилена и кислорода превышает указанное соотношение, то есть становится больше значения 1,1. Теоретически науглероженное пламя получается, когда в горелку подается 0,95 объема кислорода и менее. В этом случае ядро пламени увеличивается в объеме и теряет свои очертания. Недостаток кислорода в таком пламени приводит к неполному его сгоранию, и оно начинает коптить. Избыток ацетилена в науглероженном пламени приводит к его разложению на углерод и водород. Углерод из пламени переходит в металл, науглераживая его. Обычно науглероженное пламя применяют для сварки алюминия и наплавке твердых сплавов.

Восстановительная зона науглероженного пламени светлая и практически сливается с ядром. Температура такого пламени ниже, поэтому работать с ним более тяжело. Для перевода пламени в нормальное состояние увеличивают подачу кислорода или снижают подачу ацетилена.

Окислительное пламя получается при недостатке ацетилена, то есть соотношение ацетилен: кислород становится меньше 1,1. Практически окислительное пламя получается при объеме кислорода, превышающем в 1,3 объем ацетилена. Ядро такого пламени укорачивается и заостряется, а его края становятся расплывчатыми, цвет бледнеет. Температура такого пламени выше температуры нормального. 
Избыточный кислород окисляет железо и примеси, находящиеся в стали, что в конечном итоге приводит к хрупкости сварочного шва, пористости его структуры, обедненной марганцем и кремнием. Поэтому при сварке сталей окислительным пламенем пользуются присадочной проволокой с повышенным содержанием этих элементов, являющихся раскислителями. Самая высокая температура нормального пламени достигается в восстановительной зоне.

Примерный химический состав нормального ацетилено-кислородного пламени приведен в таблице 1. Нужно отметить, что ацетилено-кислородная смесь дает самую высокую температуру пламени. Изменение горючих газов несколько снижает температуру пламени и распределение ее по объему. Графическая зависимость изменения температур метан-кислородного и пропан-бутан-кислородного пламени представлена на рис.7.

Таблица 1

Химический состав нормального ацетилено-кислородного пламени

\begin{tabular}{|l|l|l|l|l|l|l|l|l|l|l|}
\hline \multicolumn{1}{|c|}{ Часть пламени } & \multicolumn{8}{c|}{ Содержание по сбъёму\% } \\
\hline & CO & H2 & CO2 & H2O & N2 & O2 & Прочие газы \\
\hline Вблизи конца ядра & 60 & 31 & - & - & 8 & - & 1 \\
\hline В конце восстановительной зоны & 33 & 15 & 9 & 6 & 33 & - & 4 \\
\hline Всредней части факела & 3,7 & 2,5 & 22 & 2,6 & 58 & 8 & 3,2 \\
\hline Вблизи конца факела & - & - & 8 & 2,2 & 74 & 15 & 0,8 \\
\hline
\end{tabular}
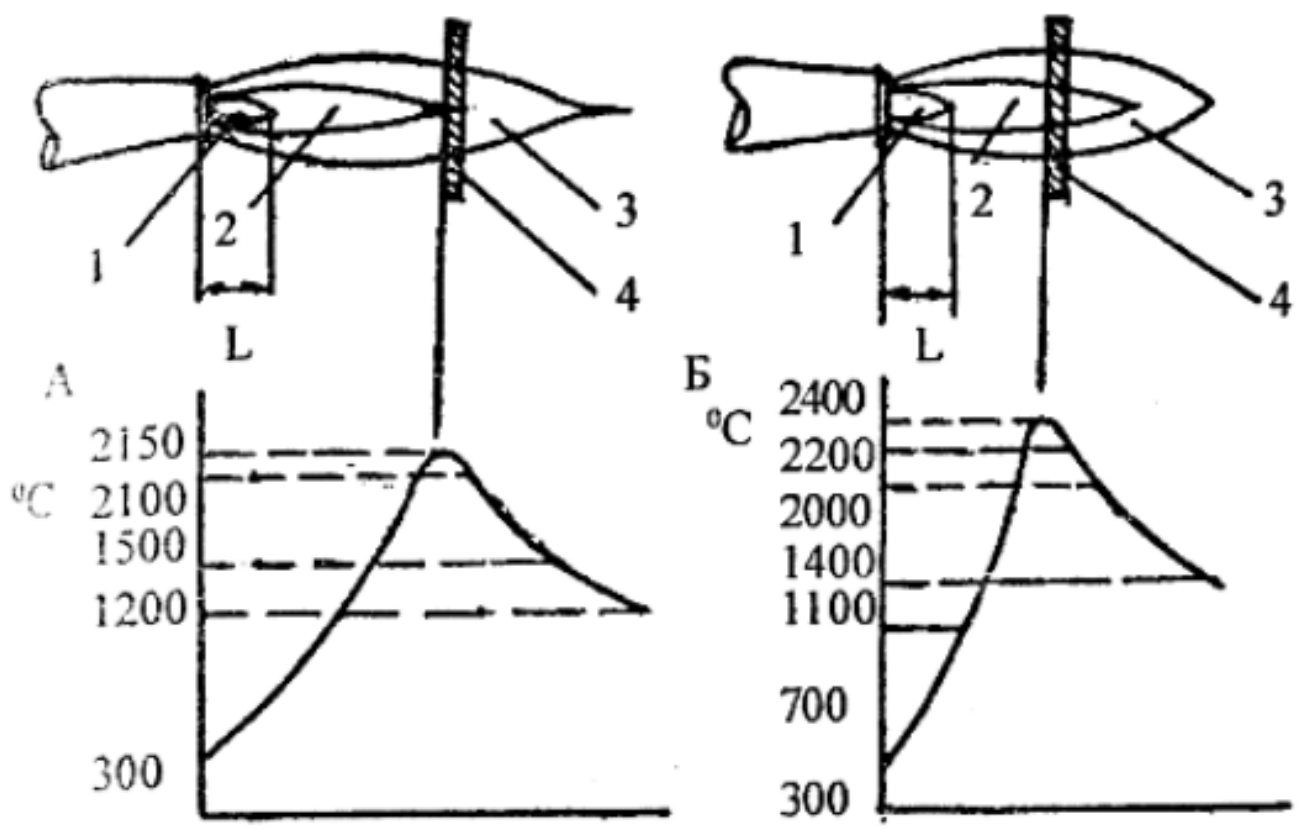

Рисунок 7 - Динамика роста температур метан-кислородного (А) и пропан-бутанкислородного пламени (Б): 1 - ядро; 2 - восстановительная зона; 3 - факел; 4 - свариваемый металл; L — длина ядра

Значительный объем тепла, сконцентрированного в пламени газовой горелки, рассеивается в окружающую среду, поэтому его коэффициент полезного действия (К.П.Д.) низок и практически не превышает 7\%. 


\section{Расход энергии пламени при газопламенной обработке}

Таблица 2

\begin{tabular}{|l|c|}
\hline \multicolumn{1}{|c|}{ Распределение энергии пламени } & Количество, \% \\
\hline $\begin{array}{l}\text { Количество тепла, раходуемого на плавление металла и поддержание } \\
\text { режима сварочного процесса }\end{array}$ & $6-7$ \\
\hline Потери тепла: & \\
\hline - от неполноты сгорания & $55-63$ \\
\hline - с отходящими газами & $13-15$ \\
\hline - на излучение и конвекцию & $9-10$ \\
\hline - на нагрев околсшовной зоны & $15-18$ \\
\hline - на искрообразование & $1-2$ \\
\hline
\end{tabular}
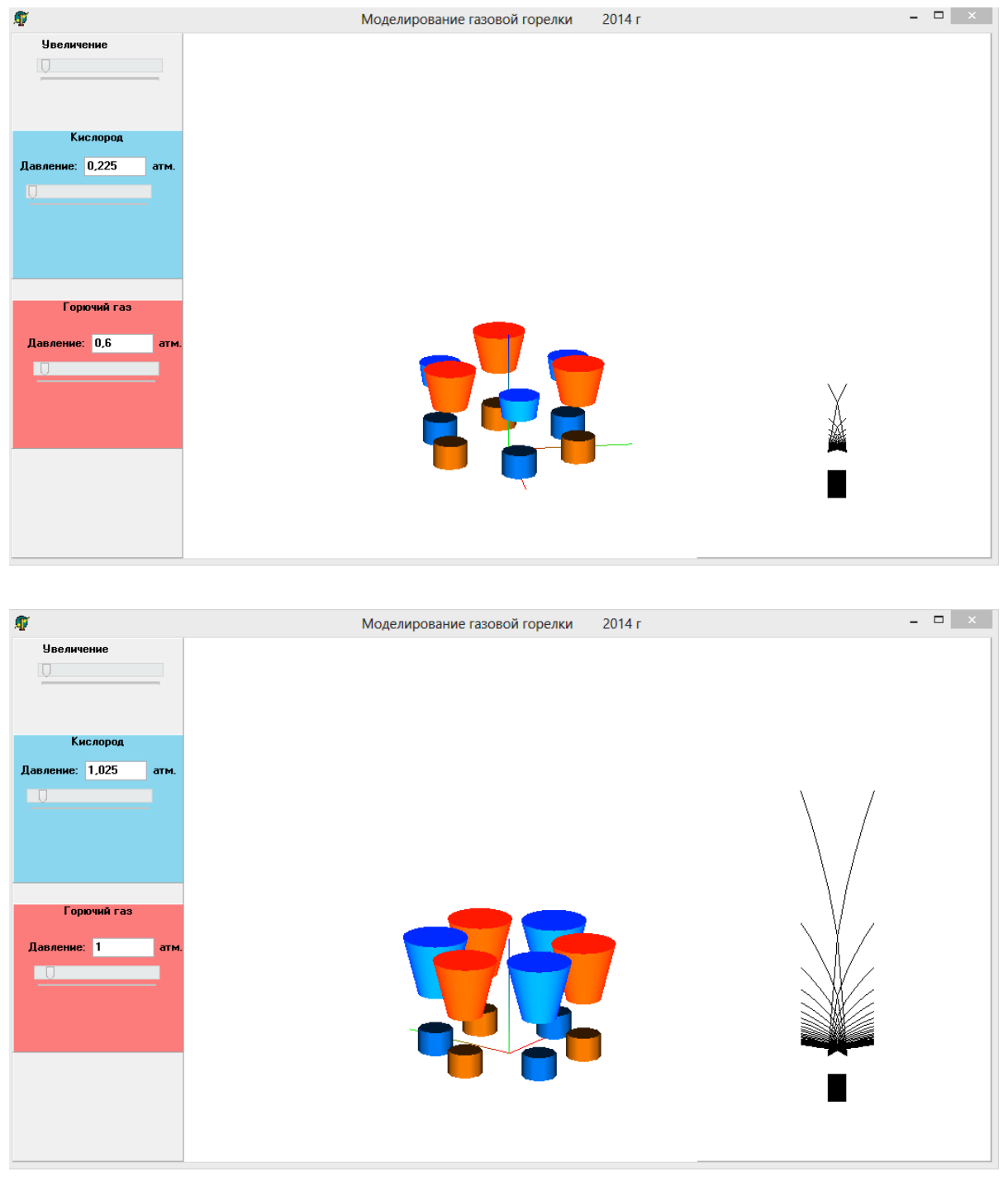

Рисунок 8 - Разработанная модель. 
Металлургические процессы в сварочной ванне при ее газопламенной обработке, а также в прилегающей к ней зоне имеют довольно сложный характер и несколько отличаются от металлургических процессов, происходящих при дуговой сварке. Это обусловлено тем, что расплавленный металл при его газопламенной обработке взаимодействует с газами, поддерживающими процесс горения. В зависимости от характера пламени, который меняет соотношение газов, изменяются и металлургические процессы.

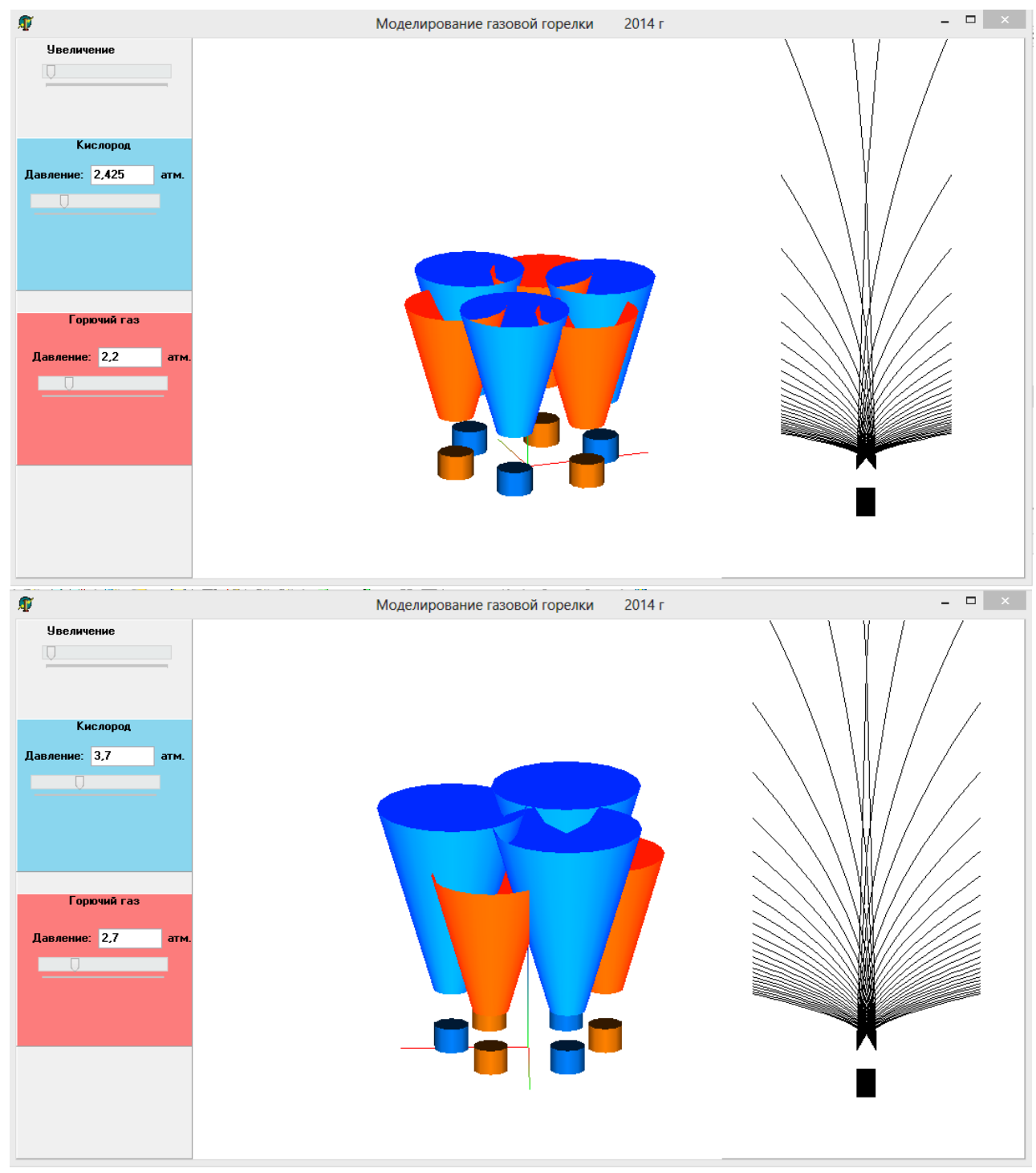

\section{Рисунок 9 - Разработанная модель (увеличение давления).}

Важной особенностью всех процессов горения является тот факт, что химические превращения должны идти с самоускорением. Горение может проявляться в виде процессов самовоспламенения и стационарного горения (распространения пламени). Самовоспламенение - это самопроизвольное возникновение пламенного горения предварительно нагретой до некоторой критической температуры горючей смеси. Процесс самовоспламенения может проявиться лишь в виде кратковременной вспышки и не обязательно сопровождается устойчивым горением.

В отличие от самовоспламенения стационарное горение характеризуется образованием устойчивого пламени. В случае ламинарного горения предварительно 
перемешанных смесей газообразного горючего с воздухом фронт пламени распространяется по холодной свежей смеси.

\section{References:}

1. Романьков Е. В., Дектерев А.А. ЧИСЛЕННОЕ МОДЕЛИРОВАНИЕ ПРОЦЕССА ГОРЕНИЯ МЕТАНА. -Сибирский федеральный университет. [Электронный pecypc] URL: http://conf.sfu-kras.ru/sites/mn2012/thesis/s012/s012-024.pdf (дата доступа: 20.05.2014).

2. Poinsot, Theoretical and Numerical Combustion, 2012 [Электронный ресурc] URL: http://ru.wikipedia.org/wiki/\%C3\%EE\%F0\%E5\%ED\%E8\%E5\#CITEREFPoinsot.2C Theoretical_and_Numerical_Combustion_2012 (дата доступа: 20.05.2014).

3. Горение [Электронный pecypc] URL: http://ru.wikipedia.org/wiki/\%C3\%EE\%F0\%E5\%ED\%E8\%E5\#cite_note-

Poinsot.2C_Theoretical_and_Numerical_Combustion_E2.80.942012.E2.80.94.E2.80. 94-51 (дата доступа: 20.05.2014).

4. Khedia K. S., Ghoniem A. F. Mechanisms of stabilization and blowoff of a premixed flame downstream of a heat-conducting perforated plate // Combustion and Flame. $\begin{array}{llll}\text { Elsevier, } & \text { 2012. - } & \text { Vol. 159. - № 3. - P. 1055-1069. - }\end{array}$ DOI:10.1016/j.combustflame.2011.10.014

5. Chen J. H. et al. Terascale direct numerical simulations of turbulent combustion using S3D // Computational Science and Discovery. — IOP Publishing, 2009. — Vol. 2. — P. 1-31. — DOI:10.1088/1749-4699/2/1/015001

6. Ламинарное распространение пламени [Электронный ресурс] URL: http://service.rintd.ru/sites/default/files/06_\%D0\%9B\%D0\%B0\%D0\%BC\%D0\%B8\% D0\%BD\%D0\%B0\%D1\%80\%D0\%BD\%D0\%BE\%D0\%B5\%20\%D1\%80\%D0\%B0\% D1\%81\%D0\%BF\%D1\%80\%D0\%BE\%D1\%81\%D1\%82\%D1\%80\%D0\%B0\%D0\%B D\%D0\%B5\%D0\%BD\%D0\%B8\%D0\%B5\%20\%D0\%BF\%D0\%BB\%D0\%B0\%D0\% BC\%D0\%B5\%D0\%BD\%D0\%B8\%206.pdf (дата доступа: 20.05.2014).

7. ЛАМИНАРНОЕ ДИФФУЗИОННОЕ ГОРЕНИЕ [Электронный ресурс] URL: http://msd.com.ua/teoriya-goreniya-i-topochnye-ustrojstva/laminarnoe-diffuzionnoegorenie/ (дата доступа: 20.05.2014).

8. ТЕОРЕТИЧЕСКИЕ ОСНОВЫ ГОРЕНИЯ ТВЕРДЫХ МАТЕРИАЛОВ [Электронный pecypc] URL: http://bent.ru/modules/Articles/article.php?storyid=207 (дата доступа: 20.05.2014).

9. Особенности природных газов [Электронный ресурс] URL: http://www.pto39.nm.ru/osobenosti.html (дата доступа: 20.05.2014).

10. Фурсенко Р.В. Стационарные режимы горения, пределы распространения и неустойчивость пламени предварительно перемешанной смеси газов при горении во встречных потоках. Диссертация на соискание уч.степ. кандидата физико-математических наук. [Электронный pecypc] URL: http://www.dissercat.com/content/statsionarnye-rezhimy-goreniya-predelyrasprostraneniya-i-neustoichivost-plameni-predvaritel\#ixzz33FF86CW6 (дата доступа: 20.05.2014). 